\title{
Controles Morfoestruturais da Compartimentação da Serra Geral: Uma Abordagem Preliminar
}

\section{Compartment of Morphostructural Controls at the Serra Geral: A preliminary approach}

\author{
Edison Fortes \\ Andréia Cavalini \\ Susana Volkmer
}

Daiany Duarte Manieri

Fernando Ricardo Santos

Universidade Estadual de Maringá

Resumo: No presente estudo, foram identificados quatro domínios morfoestruturais nominados por números romanos. O DM I (Domínio Morfoestrutural I) corresponde ao compartimento do relevo esculpido sobre as rochas basálticas da Formação Serra Geral, e que apresentam nas suas partes mais escarpadas, arenitos das formações Botucatu e Pirambóia. O DM II compreende os terrenos que abrangem os argilitos e os siltitos da Formação Rio do Rasto, situados nas partes mais baixas do compartimento, e os arenitos da Formação Botucatu, nas partes mais altas. O DM III apresenta relevos modelados sobre rochas areníticas da Formação Botucatu e Pirambóia. O DM IV corresponde ao compartimento mais rebaixado, onde predominam arenitos, siltitos e argilitos das formações Rio do Rasto e Teresina.

Palavras-chave: Morfoestruturas. Compartimentação do relevo. Unidades litoestratigráficas. Condicionamento litoestrutural.

\begin{abstract}
The present study focuses on the four morphologically structured dominions of the Serra Geral region in Southern Brazil, enumerated by Roman figures. DM I (Morphologically structured Dominion I) is built of relief components sculptured on basaltic rocks of the Serra Geral Formation, while its slope parts are composed of sandstones of the Botucatu and Pirambóia Formation. The DM II is built on ondulated planes formed by mudstones and siltstones of the Rio do Rasto Formation in its lower parts, and sandstones of the Botucatu Formation in its higher parts. The DM III again is formed on top of the sandstones of the Botucatu and Pirambóia Formation. The DM IV corresponds to a lower compartment where common sandstones, siltstones and mudstones from the Rio do Rasto and Teresina Formations can be found.
\end{abstract}

Keywords: Morphological structures. Relief compartments. Litostratographic units. Litostructural conditioning. 


\section{INTRODUÇÃO}

A Serra Geral corresponde a uma importante feição orográfica regional, que se estende desde o Estado de São Paulo até o Rio Grande do Sul; na área de estudo ela recebe a denominação de Serra da Boa Esperança, além de outras. No Estado do Paraná, essa serra constitui o limite entre o Segundo e o Terceiro Planalto (MAACK, 2002), representando, dessa forma, uma borda planáltica, que segundo IBGE (1990), exibe segmentos de relevo típicos de Cuestas, com front voltado para leste.

$O$ presente estudo constitui a etapa inicial de um projeto voltado ao estudo das bordas planálticas do Paraná, e que vem sendo realizado por uma equipe de docentes, discentes e pós-graduandos do Departamento de Geografia da Universidade Estadual de Maringá. O enfoque do trabalho é o de compreender os processos operantes nas bordas planálticas paranaenses, sob o ponto de vista neotectônico e paleoclimático.

O trabalho em questão propõe estabelecer relações litoestratigráficas e morfoestruturais da Serra Geral, na região de Faxinal, Estado do Paraná. A partir deste enfoque, pretende-se compreender a morfologia da serra em questão, e os processos operantes na depressão periférica.

O estudo do Cenozóico brasileiro (no qual pode ser incluído também o Estado do Paraná) tem sido feito, principalmente, a partir de trabalhos de cunho geomorfológico e geológico. Os trabalhos pioneiros (DE MARTONNE, 1943; KING, 1956; BIGARELLA \& AB'SABER, 1964; BIGARELLA \& MOUSINHO, 1965; AB'SABER, 1977; entre outros), enfocavam a relação das superfícies de aplainamento com seus depósitos correlativos, além da análise paleoclimática. Para os autores, o relevo brasileiro teve sua evolução associada aos processos erosivo-deposicionais ocorridos a partir do Terciário. O intervalo TerciárioPleistoceno corresponderia ao último grande período modelador do relevo, sobre o qual se instalaram os modelados de cada compartimento geomorfológico.

Os movimentos verticais associados à orogenia andina, do Mioceno Médio, tiveram profundas repercussões nas paleodrenagens do interior do continente sul-americano (POTTER, 1997). Antes do soerguimento da bacia platina os pequenos rios rumavam para oeste, desembocando no paleoceano Pacífico. Movimentos verticais posteriores permitiram a organização das drenagens e a estruturação dos rios Paraguai e Paraná. Tais rios foram sendo continuamente deslocados para sul e leste do continente.

Processos de circundesnudação periférica, associados às reativações tectônicas do Plio-Pleistoceno, levaram à exposição das rochas paleozóicas e mesozóicas da Bacia do Paraná. Eles também foram responsáveis pela formação da depressão periférica paulista paranaense e sul-matogrossense (Depressão do Alto Paraguai-Guaporé). Nessa época as drenagens sofreram uma reorganização, fornecendo sedimentos a partir de rios subseqüentes que dissecavam os terrenos e formavam as depressões periféricas, e desembocavam em rios conseqüentes. Estes, por sua vez, formavam vales epigênicos que cruzavam os fronts das cuestas até alcançarem o reverso das mesmas, quando então fluíam em direção ao rio Paraná, tanto na margem esquerda quanto na direita (FORTES, 2003).

O início da formação das depressões periféricas da bacia do Paraná ainda gera controvérsia. Um dos primeiros autores a abordar a questão foi MORAES REGO (1930 e 1932, apud AB'SABER, 1969), que admitiu uma fase de peneplanização eocênica, e uma fase de sedimentação pliocênica, aceitas por AB'SABER (1969), que atribuiu à sua gênese, processos de cir- 
cundesnudação periférica pós-cretácica.

Os eventos pós-cretáceos mencionados acima tiveram grande influência na estruturação e na compartimentação do relevo paranaense, quando no Terciário, os processos epirogenéticos soergueram as bordas da Bacia Sedimentar do Paraná. A epirogênese, que permitiu a aceleração dos processos erosivos, levou à formação das depressões monoclinais paranaenses.

\section{LOCALIZAÇÃO}

A área de estudo está compreendida entre as coordenadas $23^{\circ} 55^{\prime}$ e $24^{\circ} 30^{\prime}$ de latitudes Sul e $51^{\circ} 00^{\prime}$ e $51030^{\prime}$ de longitude Oeste (Figura 1). Corresponde à área abrangida pela folha (SG-22-C-1I) de Faxinal, Paraná, na escala de 1: 100.000 (IBGE), editada em 1967.

A área correspondente à carta de Faxinal possui cerca de $2800 \mathrm{~km}^{2}$ e abrange o município de Faxinal, Cruzmaltina, Grandes Rios, Ortigueira, Rosário do Ivaí, Rio Branco do Ivaí, Ariranha, Cândido de Abreu, Reserva e Manoel Ribas. A folha de Faxinal está articulada ao norte com a folha de Apucarana, ao sul com Cândido de Abreu, a leste com Telêmaco Borba, e a oeste com Ivaiporã.

As vias de acesso estão representadas pelas rodovias: federal BR 376, e estadual PR 272. Outras vias pavimentadas ou sem

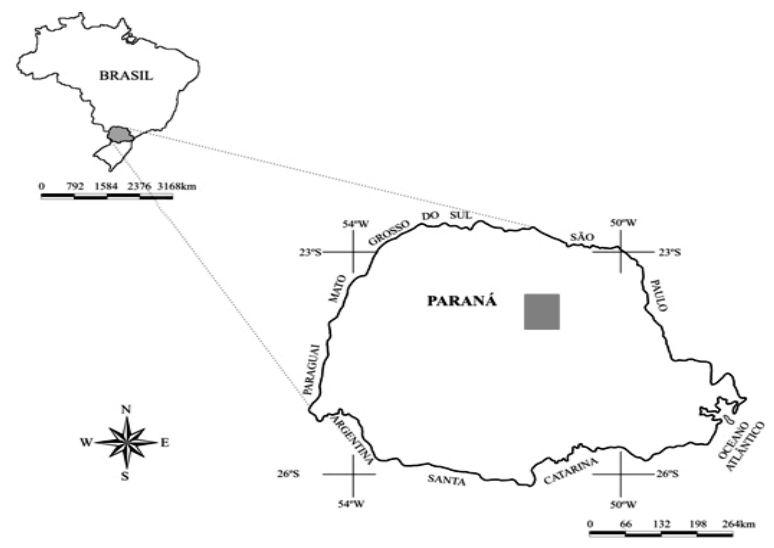

Figura 1 - Localização da área de pesquisa. pavimentação permitem acesso a toda área de pesquisa (Figura 1).

\section{METODOLOGIA}

Para a elaboração do presente estudo foi necessária a construção da base cartográfica. Dessa forma, foi feita a digitalização da carta topográfica da Folha de Faxinal (SG-22-c-ii) na escala 1:100.000 utilizandose para isso o programa AutoCad 2004.

A base topográfica digitalizada permitiu a elaboração dos mapas de declividade, hipsometria e hidrografia, utilizando-se para isso os softwares Spring 4.1 e CoreI Draw 11. Esses produtos auxiliaram na definição dos compartimentos morfoestruturais.

$\mathrm{Na}$ carta foram definidos sete perfis topográficos transversais, também vetorizados no AutoCad 2004, para que não perdesse informações e definições da topografia.

Por meio do site da Embrapa - Paraná (www.embrapa.gov.br), foram obtidas as imagens de radar (SRTM) e de satélite (LANDSAT) da área na escala de 1:100.000. A imagem de radar permitiu a observação e análise do relevo, considerando-se a análise do padrão de textura, densidade de crênulas, altimetrias e estruturas. A imagem de satélite permitiu a análise e o mapeamento de feições como hidrografia e depósitos aluvionares.

Com base nos dados supracitados, obtidos a partir da análise das imagens de radar e satélite, foi elaborado o mapa morfoestrutural Nele foram representadas a distribuição das unidades litoestratigráficas, bem como as principais feições do relevo. Esses elementos quando combinados permitiram a definição de polígonos representativos dos compartimentos morfoestruturais.

Os trabalhos de campo visaram o reconhecimento da área quanto à definição de 
compartimentos do relevo, mapeamento litoestratigráfico e checagem das informações obtidas da interpretação das imagens de radar e satélite.

\section{DISTRIBUIÇÃO ESPACIAL E RELEVO REGIONAL E LOCAL}

O Estado do Paraná encontra-se inserido em duas grandes unidades geotectônicas: o Escudo Atlântico e a Bacia Sedimentar do Paraná. Na primeira unidade afloram rochas do proterozóico, constituídas principalmente por granitos e migmatitos. Na porção oeste, encontram-se as rochas sedimentares e vulcânicas básicas da Bacia Sedimentar do Paraná, que mergulham suavemente em direção oeste.

O relevo do Estado do Paraná corresponde a uma sucessão de planaltos, classificados pelo IBGE (1990), como Patamares da Bacia do Paraná, e limitados por escarpas abruptas e descontínuas de fronts de Cuestas (Figura 2). Os planaltos formam extensas superfícies com inclinação para oeste em conseqüência do mergulho das camadas da Bacia Sedimentar do Paraná. Em decorrência do mergulho regional da estruturas, as cotas altimétricas variam de cerca de $1.200 \mathrm{~m}$ de altitude, na parte leste, para menos de $200 \mathrm{~m}$, na parte oeste.

O rio Ivaí corresponde ao principal curso fluvial que drena parcialmente a área de estudo em sua porção SE. Ele atravessa as escarpas da Serra Geral por superim- posição, e forma vales epigênicos. O rio Alonzo é outro importante curso fluvial que percorre a área de estudo de SE para NW até desaguar no rio Ivaí. O sistema de drenagem da região de Faxinal apresenta evi,dente controle estrutural representado por grandes quantidades de diques de diabásio, que atravessam a área de estudo na direção NW-SE, e por lineamentos tectônicos com direções diversas. Por esta razão, a área de estudo apresenta padrões de drenagem de tipo retangular e subdendrítico.

A borda planáltica na área-foco representa terminais escarpados, muitas vezes festonados e profundamente dissecados pela ação fluvial. Níveis escalonados na escarpa representam, representam por vezes, forte evidência da erosão diferencial atuante sobre um substrato de litologias variadas. Em outras ocasiões rupturas de declives bem marcadas ao longo das vertentes, com coberturas detríticas, representadas por blocos de arenitos e basaltos, com formas angulosas e subangulosas, denotam importante contribuição paleoclimática.

Evidências de caráter tectônico estão representadas por forte desnivelamento altimétrico dos compartimentos morfoestruturais e das unidades litoetruturais. A presença de altos estruturais demonstra importante atividade erosiva contribuindo para a geomorfogênese das bacias hidrográficas.

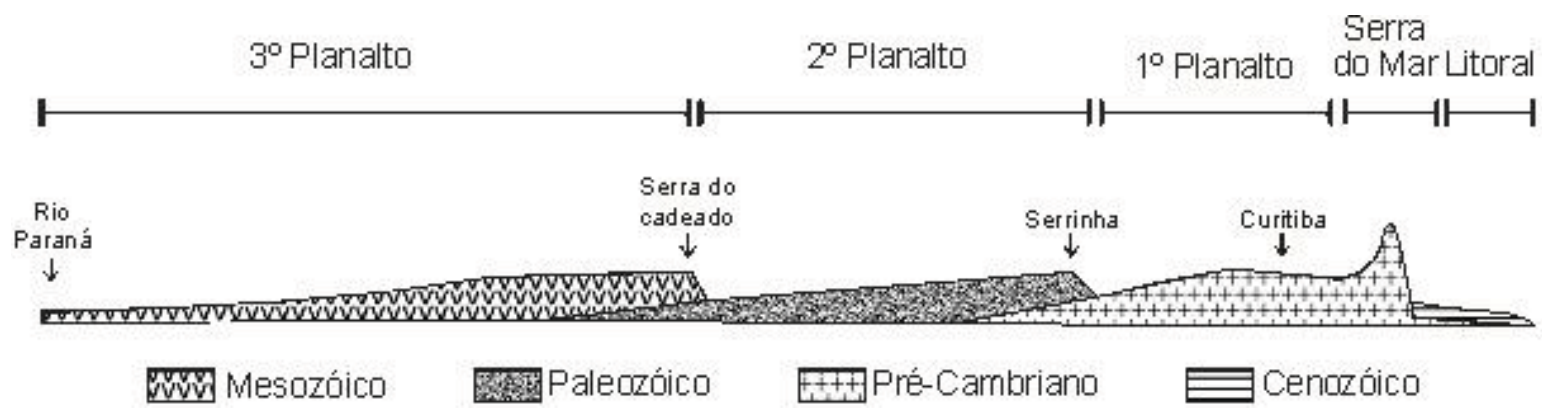

Figura 2 - Perfil topográfico esquemático do estado do Paraná (E-W) 


\section{ARCABOUÇO LITOESTRATIGRÁFICO}

Em termos litoestratigráficos, a área de estudo está representada em sua totalidade por rochas da Bacia Sedimentar do Paraná, incluindo formações geológicas de idades paleozóicas e mesozóicas (Figura 3).

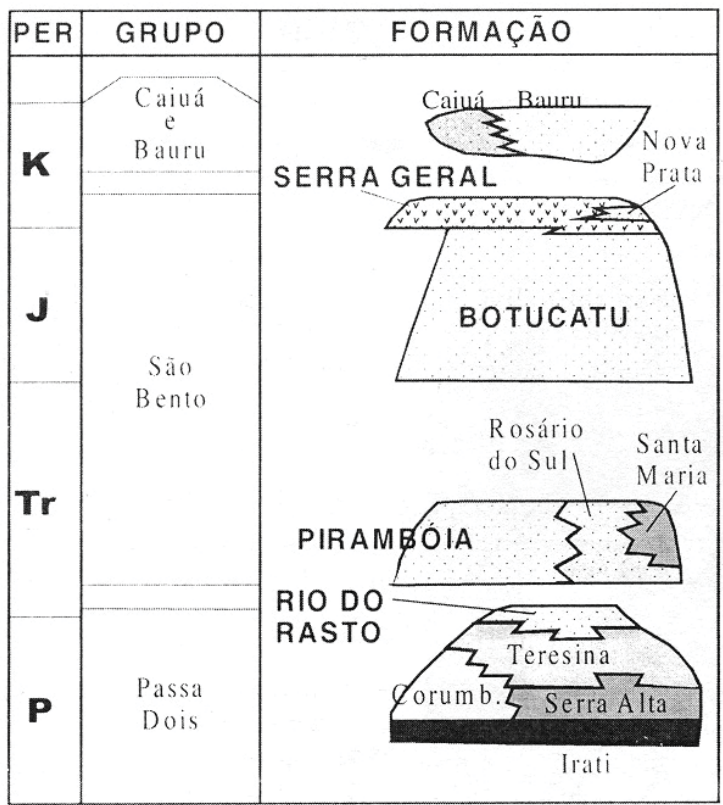

Figura 3 - Coluna estratigráfica parcial da Bacia do Paraná (STRUGALE et al, 2004).

Os sedimentos basinais da área de estudo estão representados por argilitos e siltitos da Formação Teresina, do Permiano Superior. Eles caracterizam-se pela alternância de lâminas finas de argila escura ou esverdeada, e lâminas sílticas cinza claras, constituindo laminações paralelas mal desenvolvidas, lenticulares, ou microestratificações cruzadas nas camadas predominantemente sílticas (PAULIPETRO, 1981). A Formação Teresina faz contato transicional com a Formação Rio do Rasto que lhe é sobreposta.

A Formação Rio do Rasto representa o encerramento do paleozóico na área de estudo, sendo caracterizada por uma associação de siltitos vermelhos a roxos, laminados e com aspecto pastilhado, com camadas tabulares de arenitos brancos a avermelhados, finos a muito finos, lamosos, mal selecionados, com estratificação cruzada tabular e acanalada de pequeno porte ou mesmo de aspecto maciço (STRUGALE et al., 2004). O contato com a Formação Pirambóia, sotoposta, se dá por discordância litológica com suave angularidade (SOARES, 1975).

As condições de continentalidade estão definitivamente representadas pela Formação Pirambóia, que é constituída de litologia arenosas, muito friáveis, num pacote que pode atingir $20 \mathrm{~m}$ de espessura. Predominam arenitos muito finos a finos, siltosos, brancos, com seleção regular e estratificação cruzada de baixo ângulo e sigmoidais, além de estratificações planoparalelas (STRUGALE, 2004).

A Formação Botucatu corresponde a uma sequiência arenosa, formada por arenitos avermelhados e quartzosos, finos e grãos bem selecionados, arredondados, com pouca argila na matriz. Os arenitos exibem estratificação cruzada acanalada de médio a grande porte, indicativo de sedimentação em ambiente desértico, na forma de grandes ergs (STRUGALE, 2004). Um perfil estudado na área dessa pesquisa, pela PAULIPETRO (1981), mostrou uma parte basal constituída por arenitos finos e médios, argilosos, micáceos com intercalações de camadas de siltitos arenosos de cores avermelhadas. Em direção ao topo ocorre aumento da espessura das camadas arenosas, assim como da granulometria. Presença de nível detrítico com seixos de até $2 \mathrm{~cm}$, dispersos em uma matriz que varia desde argila caolinítica a areia grossa.

Sotoposta à Formação Botucatu, e ocupando o topo da coluna estratigráfica na região estudada, ocorre a Formação Serra Geral. Esta é constituída de sucessivos derrames basálticos com ocasionais intertrapes arenosos. A Formação Serra Geral está representada por basaltos e alguns 
estratos de dacitos porfiríticos resultantes de vulcanismo fissural. Os basaltos são negros, afaníticos ou equigranulares muito finos; quando alterados apresentam cor cinza e esfoliação esferoidal. Os dacitos porfiríticos possuem matriz afanítica de cor cinza escura com fenocristais subédricos e milimétricos de plagioclásios (STRUGALE, 2004).

Rochas intrusivas básicas da Formação Serra Geral ocorrem em grande quantidade na área de pesquisa, caracterizando um nítido padrão NW-SE de diques de diabásio. A ocorrência destas rochas na paisagem é facilmente identificada, devido às extensas cristas alongadas, com vertentes de inclinação superior a 30\%, indicando o seu maior grau de resistência à erosão. $\mathrm{O}$ paralelismo de sucessivas cristas determina o controle e padrão do sistema de drenagem da área, formando vales muito encaixados e profundos.

\section{COMPARIMENTAÇÃO MORFOESTRUTURAL}

Os domínios morfoestruturais correspondem às áreas contíguas que apresentam similaridade de seus relevos e são definidos por um ou mais tipos litológicos que exercem influências no modelado. Cada um dos quatro domínios definidos na área apresenta evolução condicionada por fatores litoestruturais, tectônicos e morfoclimáticos. Os critérios analisados para estabelecer os domínios morfoestruturais foram: as litologias, o grau de dissecação do relevo, as altitudes predominantes, a declividade, as formas do relevo, as estruturas e a hidrografia.

\section{DOMÍNIO MORFOESTRUTURAL I - DM I}

Este domínio localiza-se na parte norte da área e encontra-se associado à Formação Serra Geral (foto 1). Os basaltos e os diabásios correspondem às litologias predominantes. Os arenitos das formações Botucatu e Pirambóia têm área de ocorrência secundária.

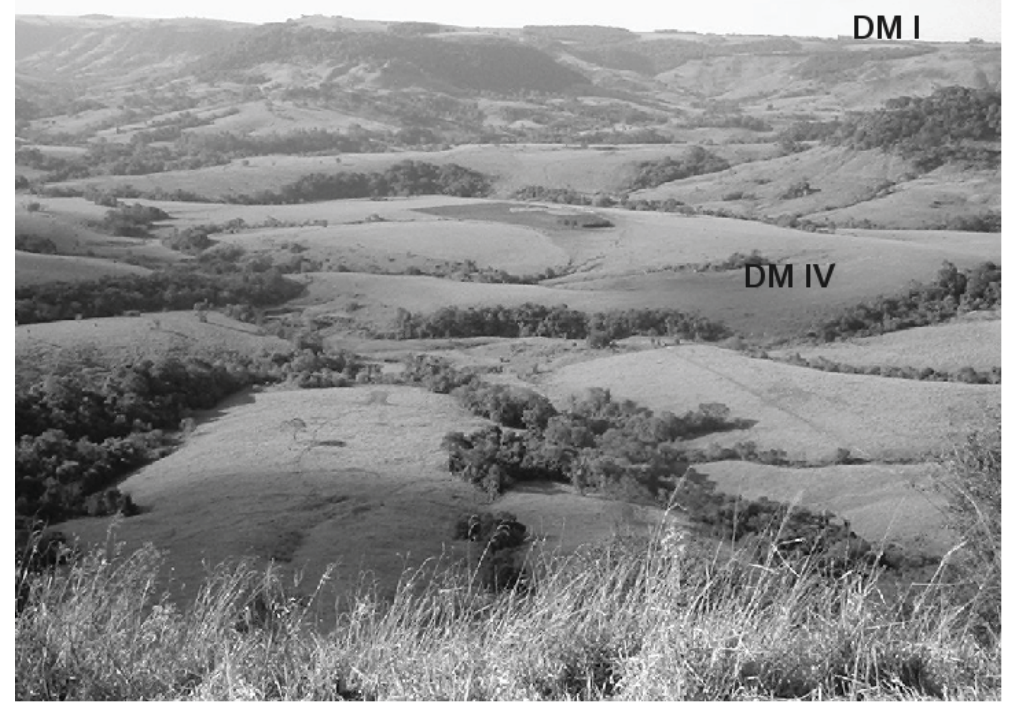

Foto 1 - Vista parcial da Serra Geral com relevo escarpado ao fundo e onde está localizado o Domínio Morfoestrutural 1. O Domínio Morfoestrutural 4 é destacado em primeiro plano pelo relevo de colinas rebaixadas, modeladas sobre arenitos e argilitos da Formação Rio do Rastro. 
está associada à magnitude da exposição na primeira, e ressaltos litológicos na segunda.

As cristas principais são sustentadas por basaltos e a crista secundária por arenitos, estes apresentando alto grau de coesão devido ao processo de silicificação.

Os padrões de drenagem domi- nantes são o dendrítico e o subdendrítico e estão associados às rochas efusivas básicas; predominam vales em forma de " $v$ ", drenados pelos rios São Pedro, Bufadeira, ribeirão da Campina, sabugueiro e rio Pereira (Figura 7).
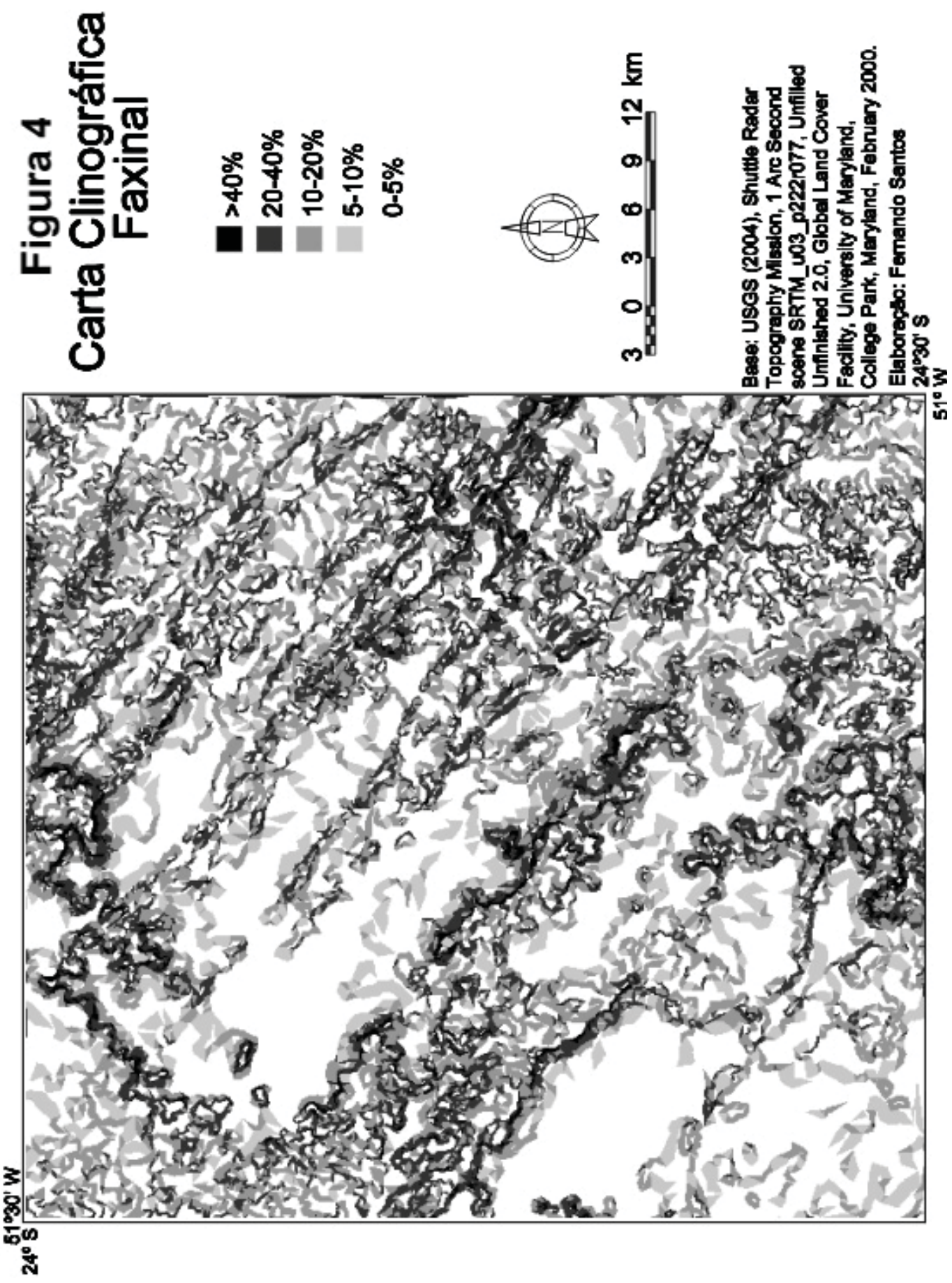

Terr@Plural, Ponta Grossa, 2 (2): 279-292 , jul./dez., 2008 

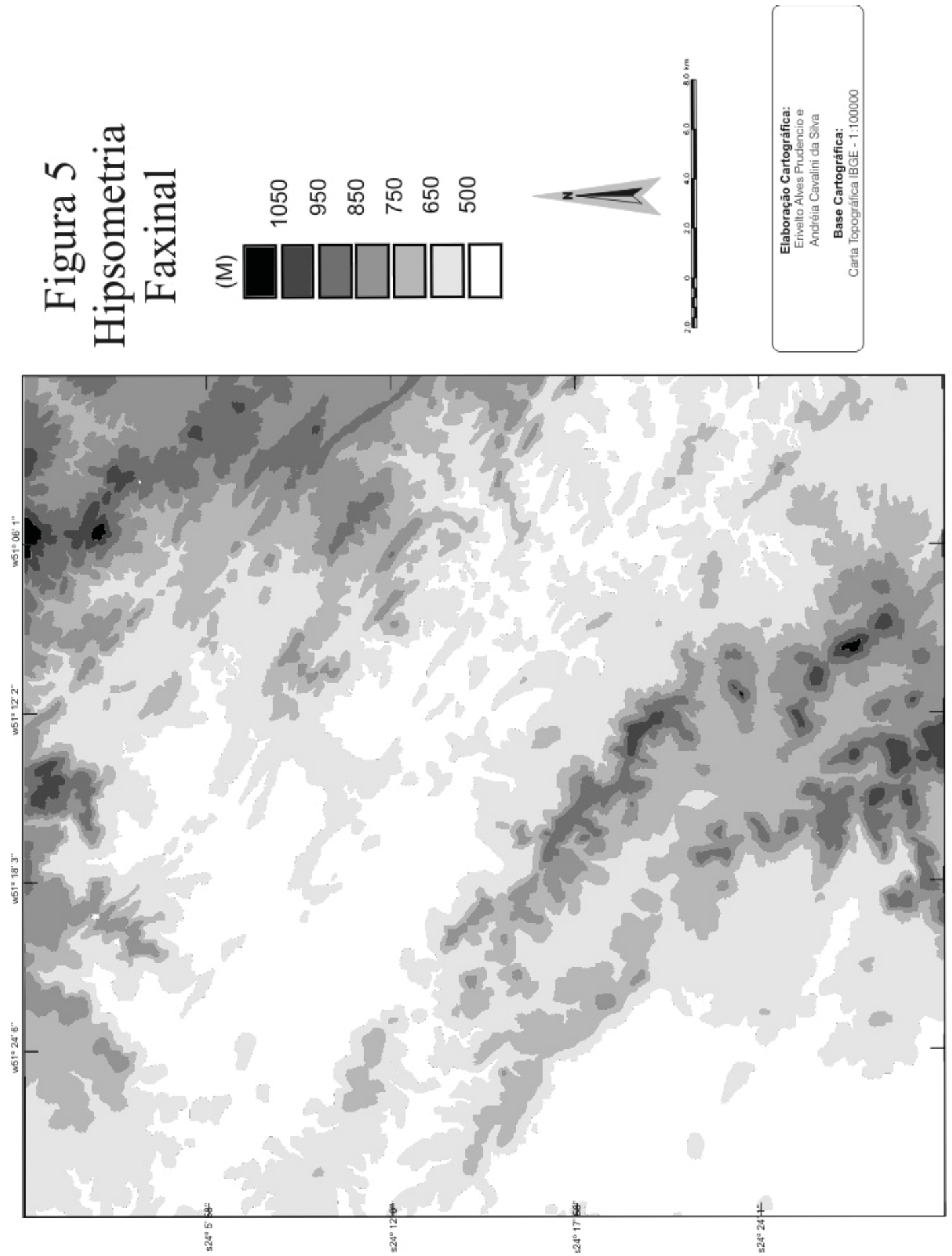

O escalonamento estrutural do relevo permite o desenvolvimento de inúmeras quedas d'água, vinculados aos níveis de derrames dos basaltos e à variação litológica (entre basaltos e arenitos). As estruturas horizontais do basalto possibilitam o de- senvolvimento de cachoeiras em degraus. As variações litológicas propiciam o desenvolvimento de quedas d'água em forma de paredões, cujo topo é constituído por basalto apresentando disjunção colunar; $o$ arenito encontra-se na base do paredão, 
onde forma grutas decorrentes da abrasão fluvial (Foto 2). O Domínio Morfoestrutural I, no contato Terceiro-Segundo Planalto Paranaense, encontra-se soerguido.

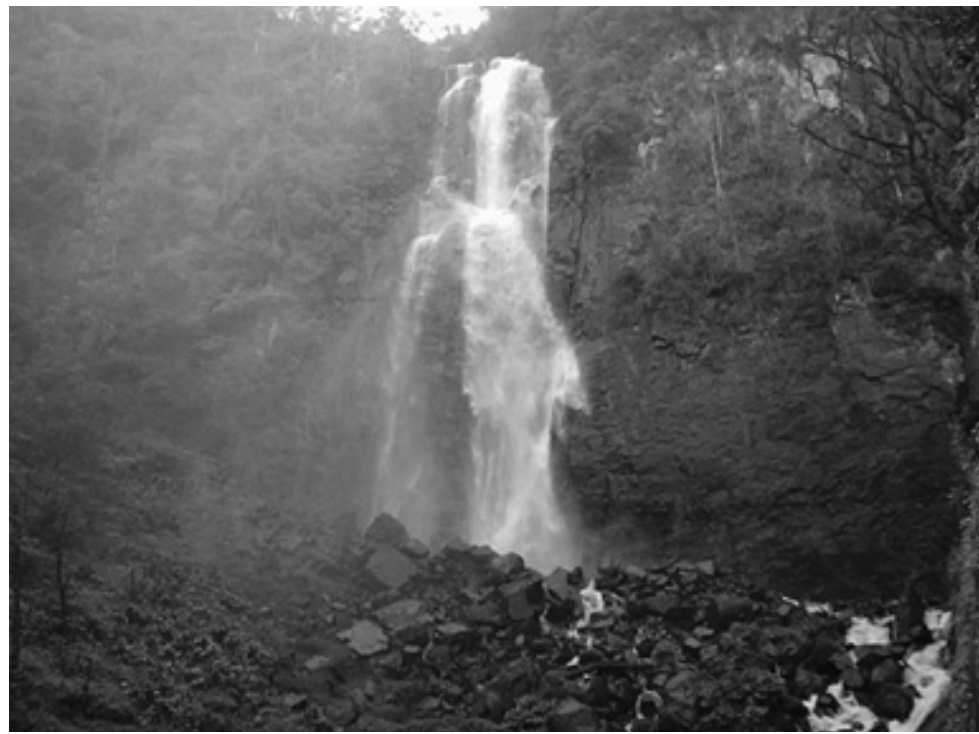

Foto 2 - Cachoeira no rio São Pedro sobre rochas basálticas da Formação Serra Geral no terço superior da encosta e arenito da Formação Botucatu na base.
Os arenitos silicificados e friáveis das Formações Botucatu e Pirambóia ocorrem neste compartimento de maneira isolada, sempre ocupando as partes mais altas da topografia, entre 750 e 1350 metros. Eles estão frequentemente truncados por diques de diabásio que orientam a dissecação do relevo (Figura 6).

O controle litoestrutural deste domínio é exercido pelas formações areníticas silicificadas da Formação Botucatu e Pirambóia (Figura 6).

A característica mais compíscua desse compartimento refere-se ao padrão de drenagem paralelo e subparalelo, de direção NW-SE, vinculado aos diques de diabásio; estes padrões ocorrem em densidade superior a todos os demais verificados na área.

\section{DOMÍNIO MORFOESTRUTURAL II - DM II}

Esse domínio se encontra na porção nordeste do mapa de compartimentação morfoestrutural (Figura 6), sendo que a unidade estratigráfica representativa do mesmo é a Formação Rio do Rasto, contendo arenitos, siltitos e argilitos (Foto 3). Enxames de diques de diabásio de direção NW-SE emprestam ao relevo, feições alongadas e elevadas, intercaladas por vales profundos, confinados e controlados por essas litoestruturas. As declividades variam de 0 a $20 \%$, e de 20 a $>40 \%$ (Figura 4). Este domínio morfoestrutural comporta a Serra da Boa Esperança e apresenta altitudes elevadas entre 750 a $>1350$ metros (Figura 5).

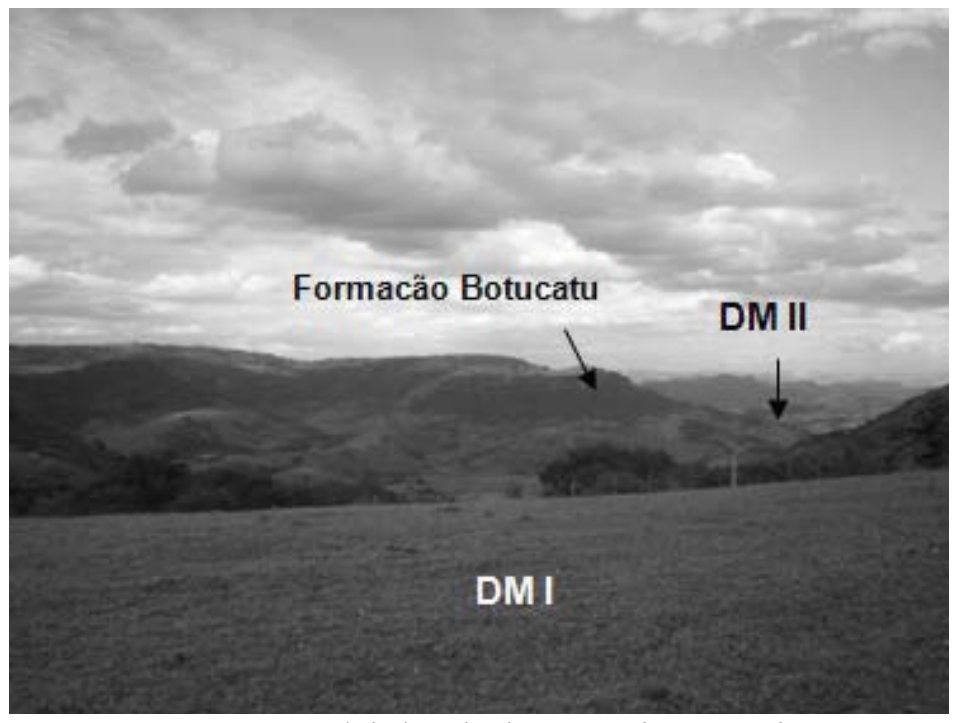

Foto 3 - Aspecto parcial da borda divisória do Segundo e Terceiro Planalto Paranaense. Em primeiro plano o Domínio Morfoestrutural I (DM I) de litologias basálticas e ao fundo relevo rebaixado do Domínio Morfoestrutural II (DM II) modelada em arenitos e argilitos da Formação Rio do Rasto. A Escarpa ao fundo corresponde a zona de falha em arenito da Formação Botucatu. 

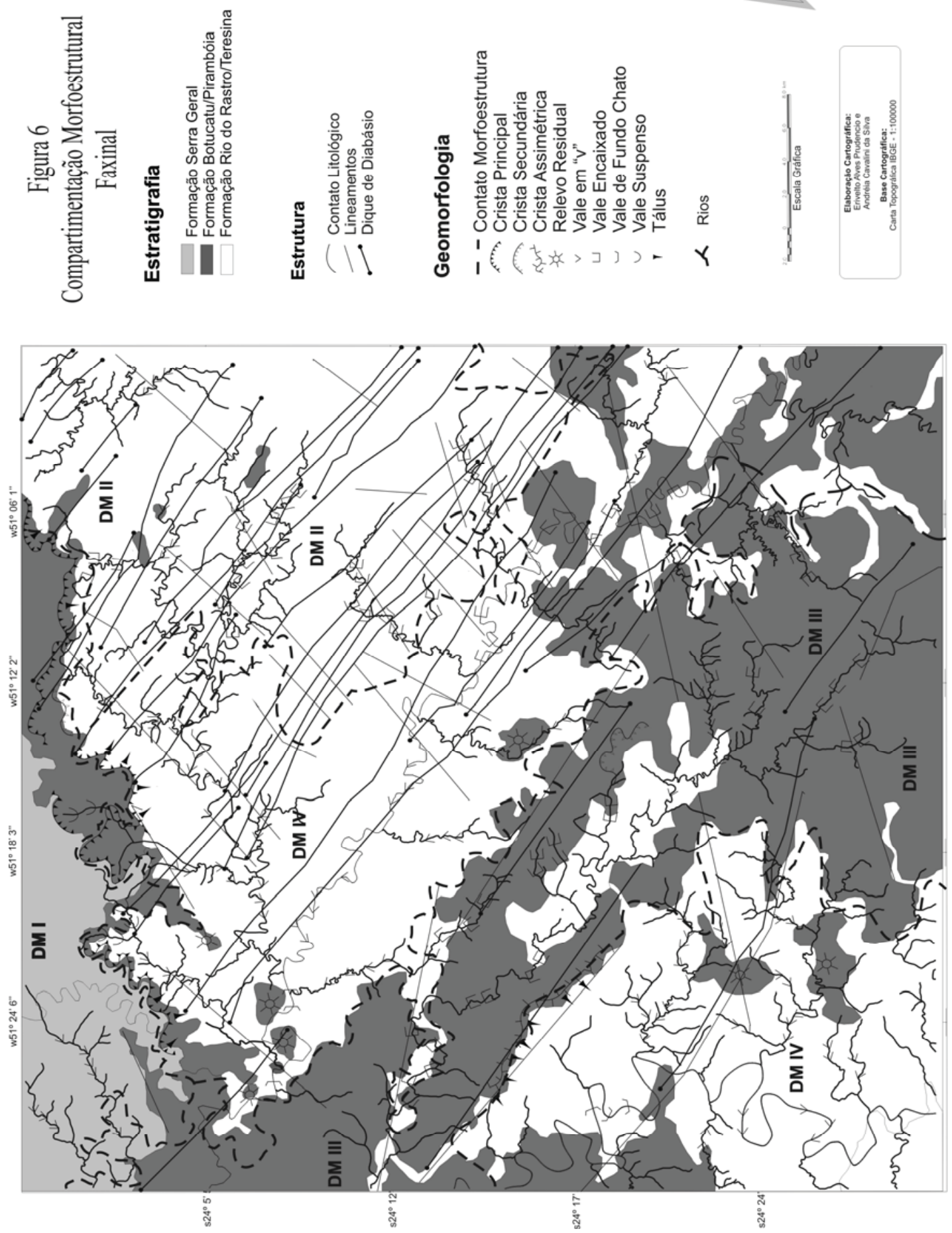

Os principais lineamentos estruturais da área são representados por traços de falha ou fraturas, de direção predominante NW-SE, e estão vinculados aos diques de diabásio. Os lineamentos secundários correspondem às fraturas de direção NE-SW; eles permitem a dissecação do relevo através do controle exercido pela rede de drenagem (Figura 7). O sistema de drenagem paralelo é de direção NWSE, evidenciando, portanto a importância dos diques de diabásio no controle desse compartimento. 

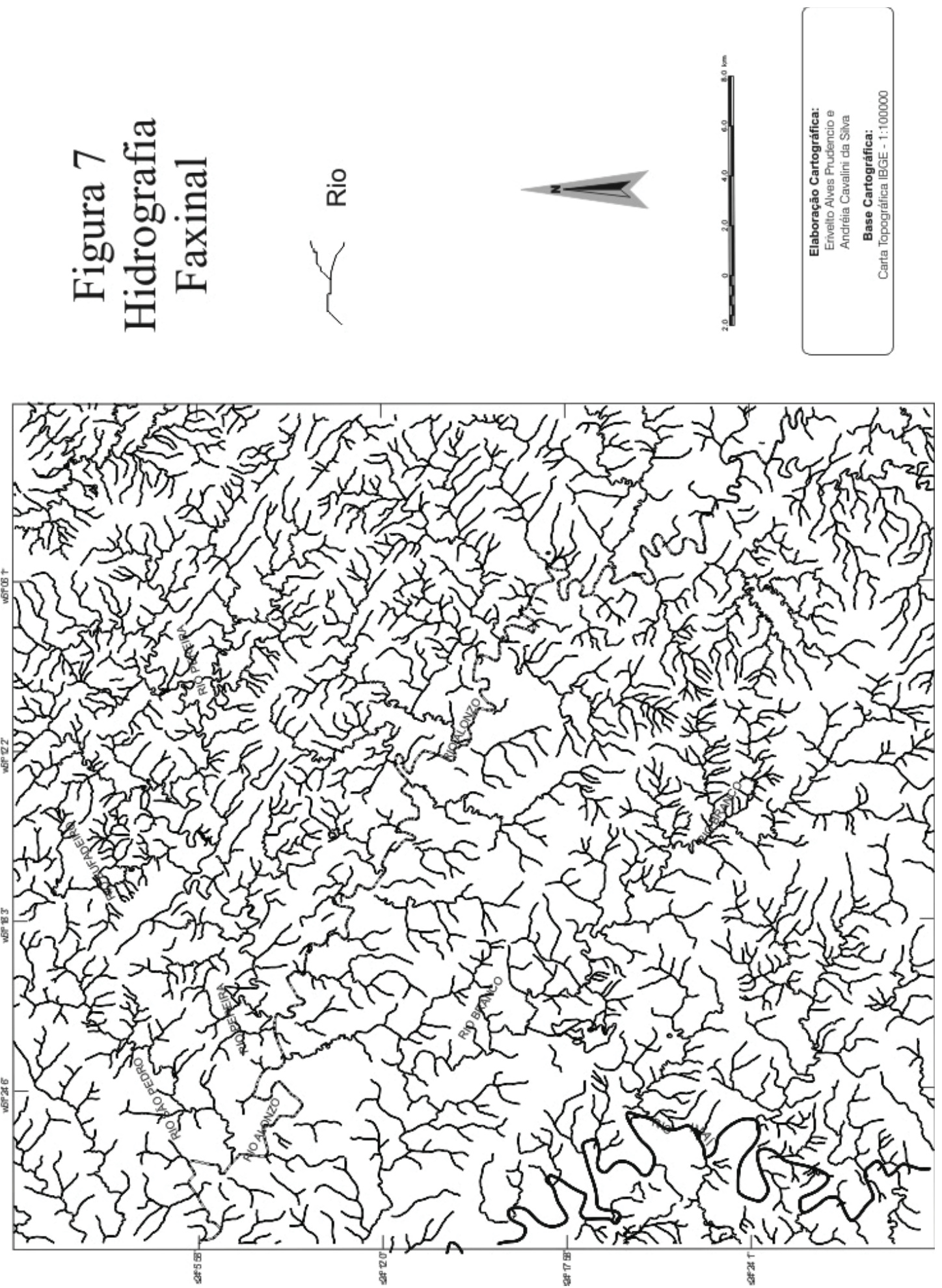
O controle tectônico é salientado pelo contato dos arenitos das formações Botucatu e Pirambóia, com os arenitos e argilitos da Formação Rio do Rasto; isto pode ser verificado em cotas de até $970 \mathrm{~m}$, junto à rodovia BR 376.

\section{DOMÍNIO MORFOESTRUTURAL III - DM III}

O domínio DM III apresenta distribuição NW-SE, estando o mesmo também associado à presença de diques de diabásio, que sustentam lateralmente os arenitos das formações Botucatu e Pirambóia (Foto 4). O relevo deste domínio é de tipo alongado, evidenciando cristas que se distribuem em altitudes que variam de 650 a 1350m (Figura 5). Essa elevação recebe localmente, as denominações de: Serra da Canela, Serra dos Porongos e Serra do Machado.

As declividades verificadas no DM III são acentuadas, variando de 20 a $40 \%$ nas serras, e inferiores a $3 \%$, no vale do rio Branco (Figura 4). O relevo é caracterizado por serras alongadas, sendo freqüentemente escarpado. Ocorrem cristas secundárias, como a da Serra dos Porongos, cujo front é voltado para o vale do rio Branco. Na Serra do Machado as cristas são assimétricas e marcam o contato morfoestrutural com o Domínio Morfoestrutural IV, na parte sudoeste (Figura 6).

O Domínio Morfoestrutural III apresenta dois compartimentos: um localizado na parte nordeste e outro na parte sudoeste; ambos estão separados pelo vale drenado pelo rio Branco, controlado por falhamento E-W (Figuras 6 e 7) que faz parte do Domínio Morfoestrutural IV.

As serras dos Porongos e do Machado exercem uma função importante no controle dos processos erosivos exercidos pelo rio Branco. Este rio se encontra limitado lateralmente pelas serras supracitadas; onde o rio Branco aprofunda o leito do vale, fazendo aflorar os arenitos e argilitos da Formação Rio do Rasto, formam-se vales encaixados (Figura 6).

O domínio Morfoestrutural III corresponde a um bloco soerguido e intensamente falhado, evidenciando afloramentos da Formação Rio do Rasto em cotas de até $850 \mathrm{~m}$, contrastando com as cotas observadas no Domínio Morfoestrutural IV, que atingem no máximo $650 \mathrm{~m}$ de altitude (Figuras 6).

\section{DOMÍNIO MORFOESTRUTURAL IV - DM IV}

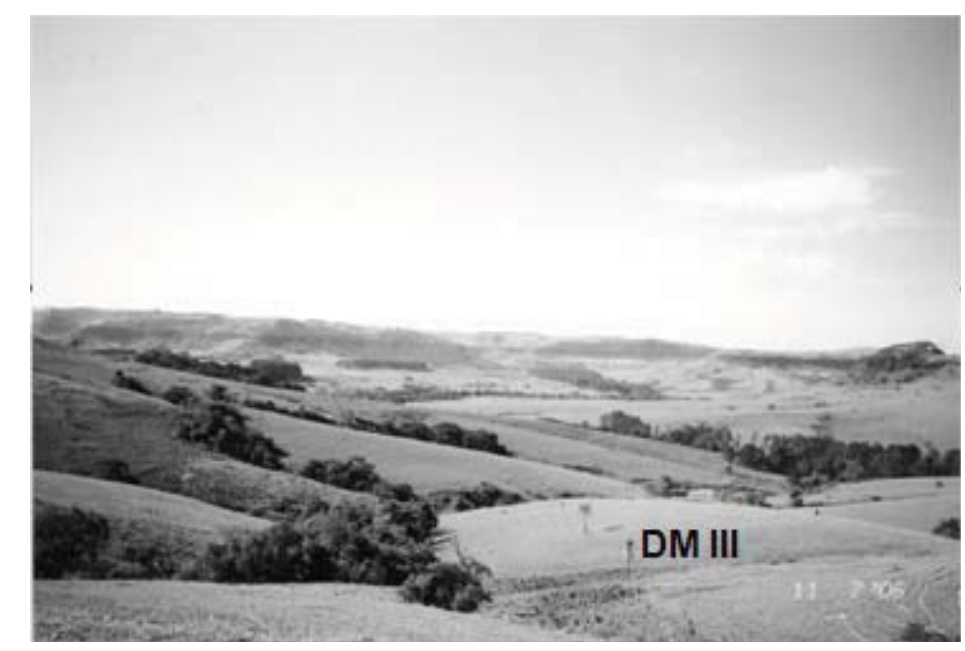

Foto 4 - Vista parcial do Domínio Morfoestrutural III, modelado sobre rochas da Formação Botucatu e Pirambóia, ao fundo relevo escarpado controlado por rochas intrusivas básicas.
O quarto domínio morfoestrutural da área corresponde a um extenso compartimento de relevo interrompido pelo Domínio Morfoestrutural III. Este domínio encontra-se na parte central e sudoeste da área em estudo (Figura 6).

O relevo do domínio DM IV é colinoso, apresentando grande quantidade de elevações residuais sustentadas por arenitos silicificados da Formação Botucatu, sobrepostos aos arenitos friáveis da Formação Pirambóia. Contudo, as litologias predominantes nesse 
domínio morfoestrutural são os arenitos e argilitos da Formação Rio do Rasto e Teresina (foto 1).

As declividades predominantes oscilam entre 0 e $3 \%$, podendo secundariamente ocorrer declividades de até $40 \%$ junto aos morros isolados (Figura 4).

Este domínio morfoestrutural representa a zona mais dissecada de toda a área de pesquisa, com altitudes variando de 300 a 650m (Figura 5).

Os controles denudacionais são comandados pelo rio lvaí, ao sul, e pelo rio Alonzo, ao norte (Figura 6).

A drenagem dominante é a de tipo paralela, que está bastante evidenciada na parte nordeste desse domínio; este padrão está associado à presença de diques de diabásio que por sua vez formam vales encaixados exibindo interflúvios alongados (Figura 7).

O controle tectônico e estrutural, do vale dos rios Ivaí e Alonzo é evidenciado pelas curvas meândricas dos canais, que formam ângulos retos denotando drenagens entalhadas em linhas de falhas ou fraturas.

\section{CONSIDERAÇÕES FINAIS}

As bordas planálticas das bacias sedimentares foram tratadas preteritamente (AB' SÁBER 1949), como sendo zonas de circundesnudação pós-cretácea, vinculadas a processo de recuo paralelo de encosta em clima semi-árido, e influenciadas por processos tectônicos tipo epirogênese. Evidências científicas atuais demonstram, no entanto, que processos de erosão diferencial e a atividade tectônica tiveram papel ativo se não determinantes na evolução dessas áreas.

$\mathrm{Na}$ área da presente pesquisa foram identificadas quatro unidades morfoestruturais, controladas litologicamente por basaltos e diques de diabásio da Formação Serra Geral, arenitos silicificados e friáveis, respectivamente das Formações Botucatu e Pirambóia, além de arenitos, siltitos e argilitos das formações Rio do Rasto e Teresina.

Os diques de diabásio constituem as estruturas mais evidentes de toda a área de pesquisa, por sustentarem o relevo de serras, condicionarem o padrão fluvial e a evolução dos vales, e controlarem a intensidade da dissecação das superfícies.

Frentes de cuestas, representadas por cornijas e depósitos de talus, formam degraus sustentados por basaltos e arenitos, com cristas em relevos escarpados.

Os Domínios Morfoestruturais II e III mostram-se como blocos tectônicos elevados, onde os arenitos e argilitos das formações Rio do Rasto e Teresina encontram-se alçados, promovendo desníveis de até 200 metros.

\section{REFERÊNCIAS}

AB’SABER, Aziz Nacib. A depressão periférica paulista: um setor das áreas de circundesnudação pós-cretácica na Bacia do Paraná. Geomorfologia, n.15, p.1-15, 1969.

AB'SABER, Aziz Nacib. Espaços ocupados pela expansão dos climas secos na América do Sul por ocasião dos períodos glaciais quaternários. Paleoclimas, IGEOG-USP, n.3, p.1-20, 1977.

BIGARELLA, João José; AB' SABER, Aziz Nacib. Palaeogeographische und Paleoklimatische Aspekte der Kaenozaikus in Sudbrasilien. Z. Geomorph., v.8, n.3, p.286-312, 1964.

BIGARELLA, João José ; MOUSINHO, Maria Regina Considerações a respeito dos terraços fluviais, rampas de colúvio e várzeas. Bol. Paran. Geogr. (Curitiba), n.16/17, p.153-97, 1965.

DE MARTONNE, Emmanoel. Problemas morfológicos do Brasil Tropical Atlântico. Rev. Brasileira de Geografia. Rio de Janeiro, v. 5, $\mathrm{n}^{\mathrm{o}} 4$, p. 532 - 550, 1943.

FORTES, Edison. Geomorfologia do Baixo Curso do Rio Ivinhema, MS: uma abordagem morfogenética e morfoestrutural. 2003. Tese (Doutorado em Geociências e Meio Ambiente). Programa de Pós-Graduação em Geociências, UNESP, Rio Claro, SP, 208p. 
EDISON FORTES, ANDRÉIA CAVALINI, SUSANA VOLKMER, DAIANY D, MANIERI E FERNANDO R, SANTOS

HASUI, Yociteru. Neotectônica e aspectos fundamentais da tectônica ressurgente no Brasil. Boletim Sociedade Brasileira de Geologia - SBG/MG, $\mathrm{n}^{\circ}$ 11, p. 1-31, 1990.

IBGE. Instituto Brasileiro de Geografia e Estatística. Geografia do Brasil: Região Sul. Diretoria de Geociências. Rio de Janeiro, 1990.

KING, Lester. A geomorfologia do Brasil oriental. Rev. Bras. Geogr., 18, p. 147-265, 1956.

MAACK, Reinhard. Geografia Física do Estado do Paraná. $3^{\circ} \mathrm{Ed}$.. Curitiba, PR. Imprensa Oficial, 2002.

PAULIPETRO. Companhia de Recursos Minerais. Geologia da Área de Faxinal - PR, Bloco SG - C (ACS - 76) - Relatório Final. 1981, 42p.

POTTER, Paul Erving. The Mesozoic and Cenozoic paleodrainage of South America: a natural history. Jour. of South America Earth Sciences, v.10, 56, p.331 - 344. 1997.

SAADI, Allaoah. Neotectônica da plataforma brasileira: esboço e interpretação preliminares. Geonomos - Revista de Geociências, v. 1, n 1 , IGC/ UFMG, 1-15, 1993

SOARES, Paulo Cesar. Divisão Estratigráfica do Mesozóico no Estado de São Paulo. Rev. Bras. Geociências, vol. 5, 1975, 229-251p.

STRUGALE, Michael.; ROSTIROLLA, Sidnei Pires; MANCINI, Fernando e PORTELA FILHO, Carlos Vieira. Compartimentação Estrutural das Formações Pirambóia e Botucatu na Região de São Jerônimo da Serra, Estado do Paraná. Rev. Bras. de Geociências, vol. 34, 2004, p.303-316.

(Recebido em 25/06/2008 e aceito para publicação em 27/11/2008) 